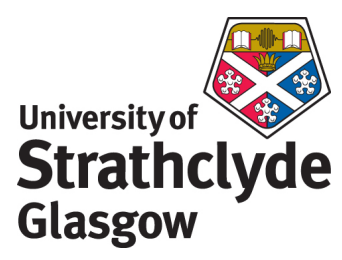

Nilsson, G.N. and Kerr, W.J. (2010) The development and use of novel iridium complexes as catalysts for ortho-directed hydrogen isotope exchange reactions. Journal of Labelled Compounds and Radiopharmaceuticals . ISSN 0362-4803

http://strathprints.strath.ac.uk/27526/

This is an author produced version of a paper published in Journal of Labelled Compounds and Radiopharmaceuticals . ISSN 0362-4803. This version has been peer-reviewed but does not include the final publ corrections, published layout or pagination.

Strathprints is designed to allow users to access the research output of the University of Strathclyde. Copyright $(C$ and Moral Rights for the papers on this site are retained by the individual authors and/or other copyright owners. You may not engage in further distribution of the material for any profitmaking activities or any commercial gain. You may freely distribute both the url (http://strathprints.strath.ac.uk) and the content of this paper for research or study, educational, or not-for-profit purposes without prior permission or charge. You may freely distribute the url (http://strathprints.strath.ac.uk) of the Strathprints website.

Any correspondence concerning this service should be sent to The Strathprints Administrator: eprints@cis.strath.ac.uk 


\title{
THE DEVELOPMENT AND USE OF NOVEL IRIDIUM \\ COMPLEXES AS CATALYSTS FOR ORTHO-DIRECTED HYDROGEN ISOTOPE EXCHANGE REACTIONS
}

\author{
Göran N. Nilsson $*^{a}$ and William J. Kerr ${ }^{b}$ \\ ${ }^{a}$ Medicinal Chemistry, AstraZeneca, R\&D Mölndal, SE-431 83, Mölndal, Sweden \\ E-mail: goran.n.nilsson@astrazeneca.com Tel+46317761423 \\ ${ }^{b}$ Department of Pure and Applied Chemistry, WestCHEM, University of Strathclyde, \\ 295 Cathedral Street, Glasgow, Scotland, UK, G1 $1 X L$. \\ E-mail:w.kerr@strath.ac.uk Fax: +44 141548 4822; Tel: +44 1415482959
}

\begin{abstract}
The preparation and application of groups of new iridium complexes are described. In particular, iridium complexes possessing phosphine ligands and a bulky $N$-heterocyclic carbene have been shown to be robust and readily handled species and have been applied in a range of directed hydrogen-deuterium and -tritium exchange processes and, in particular, with drug-like substrates or within ADMET-related studies. Overall, these new iridium(I) complexes are shown to be highly active catalysts and display catalytic activity far in excess of the industry standard, Crabtree's catalyst, with excellent levels of labelling being achieved over short reaction times and at low metal complex loadings, whilst tolerating a wide range of functional moieties. Furthermore and again in contrast to systems employing Crabtree's catalyst, the low catalyst loadings and short reaction times made possible by these emerging iridium carbene comple have delivered tritiated products with very good levels of labelling and without any appreciable by-product waste production.
\end{abstract}

\section{Keywords}

Ortho-Directed labelling, Iridium complexes, $\mathrm{N}$-Heterocyclic carbene, Deuteration, Tritiation.

\section{Introduction}

Attrition, or high failure rate, has emerged as a central problem within modern drug development. In relation to this, the design of medicinal agents, with optimal potency and pharmacokinetic properties, as well as an increased safety profile, poses a major challenge within pharmaceutical laboratories. Consequently, this has elevated the importance of and, in turn, created requirements for faster absorption, distribution, metabolism, excretion and toxicology (ADMET) methods and, therefore, for more extensive use of radiolabelled compounds. To meet these demands, the development of new and more efficient hydrogen isotope labelling techniques is essential.

One of the most effective ways to follow drug metabolism is to use site-specific labelling, most conveniently with a heavy isotope of hydrogen or carbon. Within the field of hydrogen isotope exchange (HIE) the ideal situation would be to utilise substoichiometric quantities of a catalyst to carry out the required transformation on a fully 
functionalised target molecule. In this regard, $\mathrm{C}-\mathrm{H}$ activation using organometallic species has grown to become an area of widespread significance in organic synthesis and ortho-C-H activation (Scheme 1) has been particularly important as part of HIE endeavours.

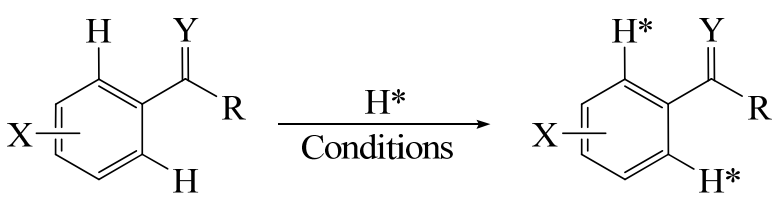

Scheme 1. Ideal hydrogen isotope exchange process.

Crabtree's catalyst (1, Figure 1), ${ }^{1}$ designed originally for the hydrogenation of olefinic double bonds, is by far the most widely used species in HIE labelling. In relation to this, the isotopic incorporation and ortho-regioselectivity is high for a wide variety of molecules possessing low to medium complexity. ${ }^{2}$ However, the scope of $\mathbf{1}$ is limited by a number of factors. First of all, dichloromethane (DCM) is usually the only solvent that is tolerated with this catalyst. In addition, bulky substituents in the vicinity of the targeted hydrogen unit inhibit exchange; inactive iridium dimers and trimers are known to form in solution, particularly when directing unit complexation is hindered; and some functional groups do not deliver any appreciable degree of labelling. ${ }^{3,4}$ Furthermore and perhaps most importantly in a practical sense, high loadings of Crabtree's catalyst 1 (i.e. equimolar or higher) are often required to deliver effective levels of exchange, due to unproductive complexation with non-directing substituents within a given molecule. Consequently and with specific regard to tritiation processes, these high metal complex loadings lead to large amounts of volatile labelled cyclooctane and/or cyclooctene as undesirable by-products. Such radioactive by-product formation can be prevented by pre-activation of the catalyst with hydrogen, ${ }^{5}$ however this introduces an extra step within the overall practical process and leads to a less straightforward labelling procedure.

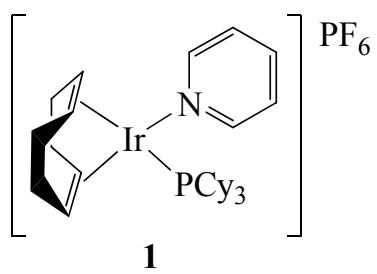

Figure 1. Crabtree's catalyst.

The literature in the area of directed HIE overall is well covered both in this current edition of the journal and in a previous special edition in memoriam of John R. Jones. ${ }^{6}$ The HIE reaction and other labelling techniques have recently been reviewed, ${ }^{7,8}$ with a range of complexes of $\mathrm{Pt}, \mathrm{Rh}, \mathrm{Ru}$, and Ir having been explored most widely. More specifically, a good number of independent research teams, particularly within the pharmaceutical industry, have further developed and used HIE processes with $\operatorname{Ir}(\mathrm{I})$ complexes. For example, Heys describes the employment of Raman spectroscopy for monitoring tritiation within such HIE (and related) reactions. ${ }^{9}$ A recent publication also describes meta-substituent effects on organoiridium-catalysed ortho-hydrogen isotope exchange and a new mechanistic route for the HIE reaction. ${ }^{10}$ Crabtree's complex 1 has also been utilised in conjunction with rhodium black to improve the activity of this 
catalyst species. ${ }^{11}$ An alternative iridium(I) system, ${ }^{12}$ which can be utilised in DMF or DMA, has also been developed and is useful for certain functional groups where the common industrial practice ${ }^{13}$ of utilising $\mathbf{1}$ in dichloromethane is impractical. It should also be noted that the limited diversity of solvents that can be used in conjunction with Crabtree's catalyst $\mathbf{1}$ is often a drawback and limits the scope of such methods, since many potential drug candidates are insoluble in DCM. The use of ionic liquids is one solution but the levels of incorporation into substrates of somewhat elevated polarity remain only moderate. ${ }^{14}$ Another problem is the formation of catalyst-derived labelled impurities, although this can be somewhat avoided by the use of a polymer-supported solid phase $\operatorname{Ir}(\mathrm{I})$ catalyst. $^{15}$ In addition to ortho-exchange, labelling into suitably positioned methyl or methylene units ${ }^{13}$ has been known since the early days of the HIEtechnique. $^{16}$

\section{Pincer Complexes}

In efforts to expand the HIE-area, research within the AstraZeneca R\&D laboratories, Mölndal, investigated whether new Ir(III) complexes could be applied effectively, especially relative to $\mathbf{1}$. The initial approach was based on the preparation of novel pincer complexes. Such species possess a tridentate, so-called, pincer ligand around a metal centre. ${ }^{17,18}$ In relation to this, Moulton and Shaw reported pioneering work on the synthesis of iridium PCP-pincers in the mid-1970's. ${ }^{19}$ This work prompted the research groups of Kaska and Jensen, ${ }^{20}$ Goldman, ${ }^{21}$ Leitner, ${ }^{22}$ and Brookhart ${ }^{23}$ to investigate their use as catalysts for the dehydrogenation of hydrocarbons. Hartwig has also reported the application of iridium PCP-pincers for $\mathrm{N}-\mathrm{H}$ activation in ammonia. ${ }^{24}$ The possibility to tune the electronic and steric properties of the pincer ligand, combined with the strong coordination of the iridium atom within a PCP-pincer complex (Figure 2), prompted us to investigate their ability to catalyse HIE.

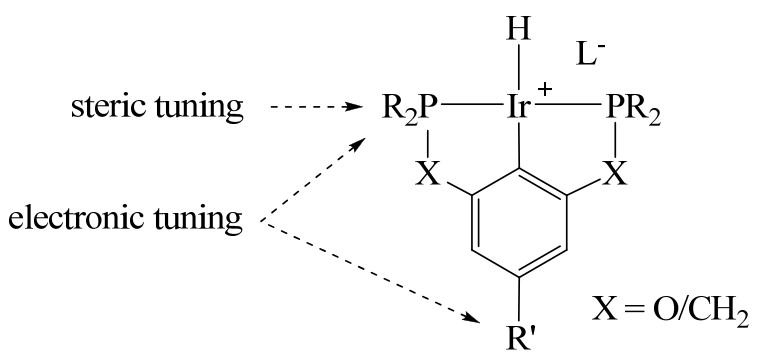

Figure 2. Tuneable sites of an Ir(III)-PCP-pincer complex.

Based on this rationale, we prepared a small series of novel iridium-pincer complexes, ${ }^{25}$ with Leitner divulging details of a ruthenium-pincer complex for use in HIE reactions at around the same time. ${ }^{26}$ Whilst our Ir species showed some good to moderate activity in directed deuterations with a small selection of substrates, these Ir-pincer complexes did not enhance the HIE processes in a general sense when compared to Crabtree's catalyst 1. Accordingly, we did not pursue this area further at this stage, preferring a new collaborative strategy using novel iridium carbene species, which were emerging from the Kerr laboratory at the University of Strathclyde, Glasgow, UK. 


\section{Phosphine $\mathrm{N}$-Heterocyclic Carbene Complexes}

A range of relatively diverse iridium-based species have been utilised within labelling processes as depicted by the general reaction in Scheme 1, with each complex showing varying degrees of efficacy. ${ }^{27}$ Based on careful consideration of the steric and electronic characteristics of the associated ligand systems, it was believed that new iridium complexes, possessing a bulky $N$-heterocyclic carbene (NHC) and an appreciably encumbered phosphine, would potentially serve to mediate efficient HIE processes. Additionally, if fully functionalised drug-like molecules of interest could be applied, this would also eliminate the need for any extra synthetic steps and avoid practical problems during reaction work-up and product isolation. In relation to this, Nolan $^{28}$ and Buriak ${ }^{29}$ have shown that complexes of the type $\mathbf{2}$ and $\mathbf{3}$, respectively (Figure 3), are useful as hydrogenation catalysts. In particular, it has been noted that ligands of increasing bulk within species of type $\mathbf{3}$ may prevent the formation of inactive iridium clusters or promote the existence of active Ir-based monomeric species, ${ }^{29}$ in turn, leading to metal complex activation within the hydrogenation processes investigated.
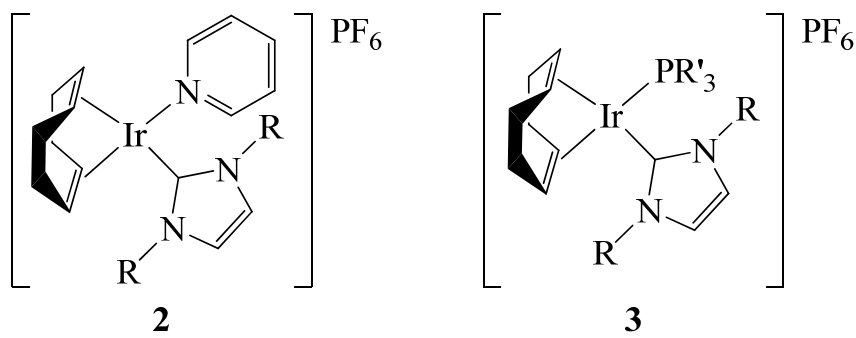

Figure 3. Modified iridium complexes possessing an $N$-heterocyclic carbene ligand.

Based on all of the above, initial efforts within the Kerr laboratories focused upon the preparation of iridium complexes with even greater steric demand around the metal centre. The specific novel complexes which were targeted possessed the appreciably hindered NHC, 1,3-bis(2,4,6-trimethylphenyl)imidazol-2-ylidene (IMes), alongside the phosphines, $\mathrm{PPh}_{3}, \mathrm{P}\left(\mathrm{CH}_{2} \mathrm{Ph}\right)_{3}$, and $\mathrm{PMe}_{2} \mathrm{Ph}$.

\section{Preparation of the Targeted Novel Iridium Carbene Complexes}

In terms of access to the desired complexes, despite describing routes to related species, Buriak had been less successful in attempts to prepare compounds possessing both a relatively bulky phosphine and a more sterically-demanding NHC. ${ }^{29}$ In contrast, using in situ generation and introduction of the NHC ligand, in combination with a relatively non-coordinating solvent such as benzene in the initial steps, led to the delivery of the desired novel iridium complexes $\mathbf{4 a}, \mathbf{4 b}$, and $\mathbf{4 c}$ (Figure 4 ) ${ }^{30}$ since isolation and handling of the carbene ligand is avoided by the established synthetic strategy, no glove box techniques are required. It is important to note, however, that the reaction solvents need to be dry and oxygen-free. Each of the complexes is strongly red/orange-coloured and all are air- and moisture-stable solids. The synthesis procedure for the preparation of the new carbene complexes is outlined in Scheme 2. 


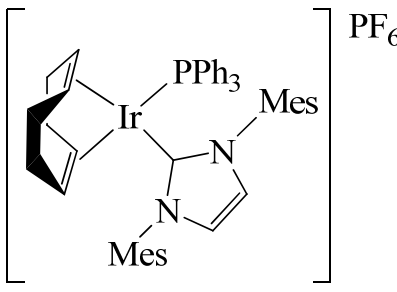

4a

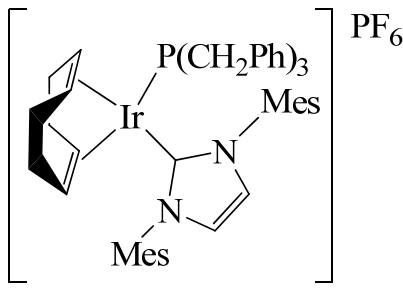

4b

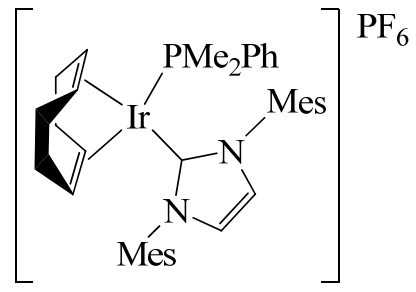

$4 \mathbf{c}$

Figure 4. New iridium complexes possessing a sterically-demanding NHC and phosphine.

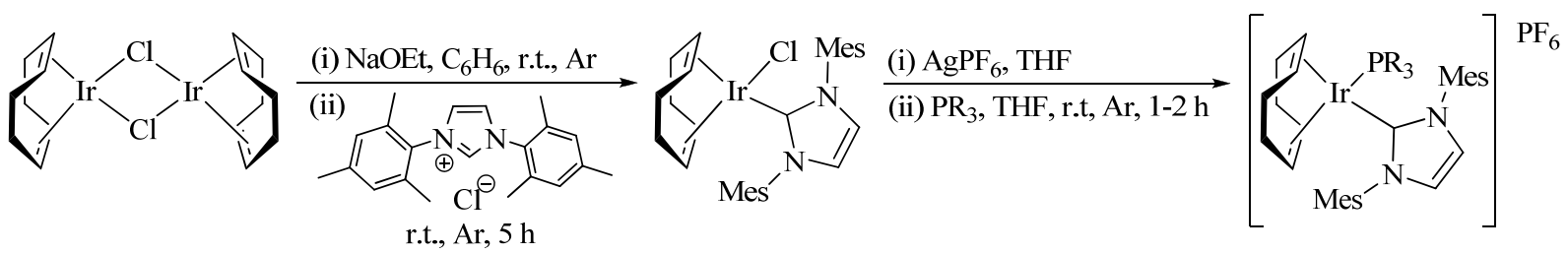

Scheme 2. General preparative route for the formation of the new iridium complexes.

\section{HIE Outcomes with the New Iridium Carbene Complexes}

When applied to a series of substrates, these robust and really very readily handled complexes, 4a-c, were shown to be highly active catalysts within directed HIE processes. Indeed, these species revealed catalytic activity in such exchange processes far in excess of the industry standard, Crabtree's catalyst, with excellent levels of labelling being achieved over short reaction times $(<90 \mathrm{~min})$ and at very low metal complex loadings (down to $0.5 \mathrm{~mol} \%$ ). ${ }^{30}$ These catalysts also displayed the ability to perform selective labelling via a five-membered metallocyclic intermediate (5-mmi), over a six-membered metallocyclic intermediate (6-mmi). One further practical benefit relates to the prolonged stability of these complex species; for example, following storage under an air atmosphere at room temperature for over 8 months, complex 4c remained significantly active in delivering 95\% D incorporation (over both orthopositions) within $\mathrm{N}, \mathrm{N}$-diethyl para-toluamide after $16 \mathrm{~h}$ at room temperature in DCM (5 mol\% loading). ${ }^{30}$

It should be noted at this stage that concurrent with the work in the Kerr laboratories, Powell et al. divulged the first use of Ir phosphine/NHC species in HIE processes, with the application of the Buriak IMe $/ \mathrm{PBu}_{3}{ }_{3}$ complex $\left(3: \mathrm{R}=\mathrm{Me} ; \mathrm{R}^{\prime}=\mathrm{Bu}^{\mathrm{n}}\right)$. Using this species at relatively high 2.2 equivalent $(220 \mathrm{~mol} \%)$ loadings, with a small range of substrates, provided levels of labelling which were equivalent to or better than those seen with 1 under equivalent conditions. ${ }^{31}$ When the same $\mathrm{IMe} / \mathrm{PBu}_{3}{ }_{3}$ catalyst was employed at appreciably lowered catalyst loadings of $5 \mathrm{~mol} \%$ with acetophenone over $16 \mathrm{~h}$, we observed significantly lowered levels of deuterium incorporation $(<5 \%$ based on minimum levels of detection). ${ }^{30}$

With specific regard to more drug-like or ADMET-related studies, Schemes 3, 4, and 5 show a summary of results obtained from a series of further endeavours with the new iridium carbene catalysts. In these studies standard hydrogen isotope exchange conditions were used with $2.5-5 \mathrm{~mol} \%$ of the catalyst and 1 atmosphere of deuterium or tritium gas for the given reaction time. As shown in Scheme 3, the sanofi-aventis 
antiandrogen, nilutamide, used for late-stage prostate cancer, is labelled to an excellent level of $98 \% \mathrm{D}$ ortho to the nitro unit with only $2.5 \mathrm{~mol} \%$ of catalyst $4 \mathbf{c}{ }^{32}$ In addition, this substrate also provides a further example of preferential labelling via a 5-mmi over a 6-mmi, with only $6 \%$ and $12 \% \mathrm{D}$ incorporation being observed at positions a and $\mathrm{b}$, respectively.<smiles>CC1(C)NC(=O)N(c2ccc([N+](=O)[O-])c(C(F)(F)F)c2)C1=O</smiles>

Nilutamide

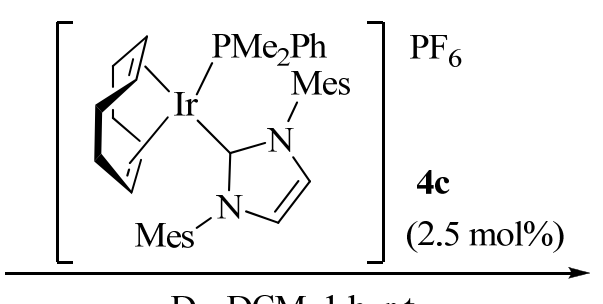

$\mathrm{D}_{2}$, DCM, 1 h, r.t.<smiles>[2H]c1c([2H])c([N+](=O)[O-])c(C(F)(F)F)c([2H])c1N1C(=O)NC(C)(C)C1=O</smiles>

a: $6 \%$; b: $12 \%$; c: $98 \%$

Scheme 3. Labelling of nilutamide (sanofi-aventis) with complex $4 \mathbf{c}(2.5 \mathrm{~mol} \%)$.

Niclosamide, the Bayer AG anthelmintic agent, is a benzanilide derivative possessing hydroxyl, chloro, and nitro functionalities. Based on the illustration in Scheme 4, positions a, b, and $\mathrm{d}$ are all expected to label via a $5-\mathrm{mmi}$, whereas position c would label through a 6-mmi, providing the potential for further selectivity. Despite this, and the good percentages of D incorporation achieved over all four sites, the level of selectivity observed was really rather low with 5 mol\% of complex $4 \mathbf{a}$ over $1 \mathrm{~h}$ at room temperature. ${ }^{32}$ Having stated this, it is worth noting that positions a and b, both of which are ortho to the nitro group, are not labelled to the same degree. Indeed, the D uptake at position a, adjacent to both the nitro and chloro units, is $10 \%$ higher than at position $b$, suggesting that weak Ir ligation to the chloro unit enhances the directing effect for this position.

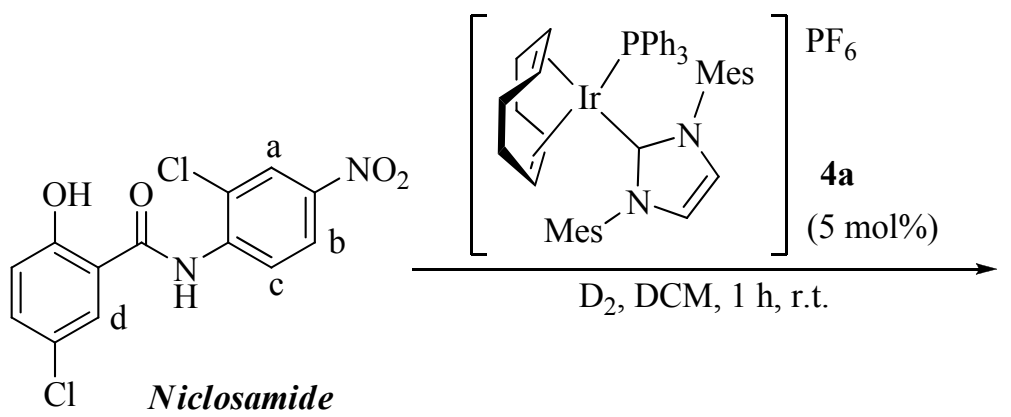<smiles>[2H]c1c([2H])c([N+](=O)[O-])c(Cl)c([2H])c1NC(=O)c1c(O)ccc(Cl)c1[2H]</smiles>

a: $65 \%$; b: $55 \%$; c: $52 \%$; d: $62 \%$

Scheme 4. Labelling of niclosamide (Bayer AG) with complex $4 \mathbf{a}(5 \mathrm{~mol} \%)$.

Following the success of the new iridium carbene species for the incorporation of deuterium, we were keen to apply the same class of complexes in hydrogen-tritium exchange reactions to introduce this widely used radioactive label. This has now been widely and successfully achieved in our laboratories. As an example of this and as illustrated in Scheme 5, when $N, N, 4$-trimethylbenzamide 5 was employed in conjunction with complex $\mathbf{4 b}(5 \mathrm{~mol} \%), 31 \%$ of the sample possessed one tritium atom after only $2 \mathrm{~h}$ at room temperature. As shown by the tritium-NMR in Figure 5, as anticipated, the tritium was incorporated into the aromatic ring (7.33 p.p.m.), with a small amount of 
tritium appearing within the amide methyl units at approx. 3 p.p.m. In addition to this, due to the low catalyst loading and short reaction time, the tritium-NMR also shows this process to be extremely clean, with no tritiated by-products being observed.<smiles>Cc1ccc(C(=O)N(C)C)cc1</smiles>

5

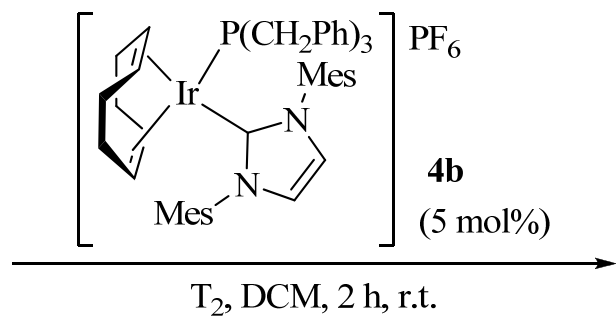

$\mathrm{T}_{2}$, DCM, 2 h, r.t.<smiles>Cc1cc(I)c(C(=O)N(C)C)c(I)c1</smiles>

$\mathrm{T}_{1}: 31 \% ; \mathrm{T}_{2}: 5 \%$

Scheme 5. Tritiation of an amide substrate with complex $\mathbf{4 b}(5 \mathrm{~mol} \%)$.

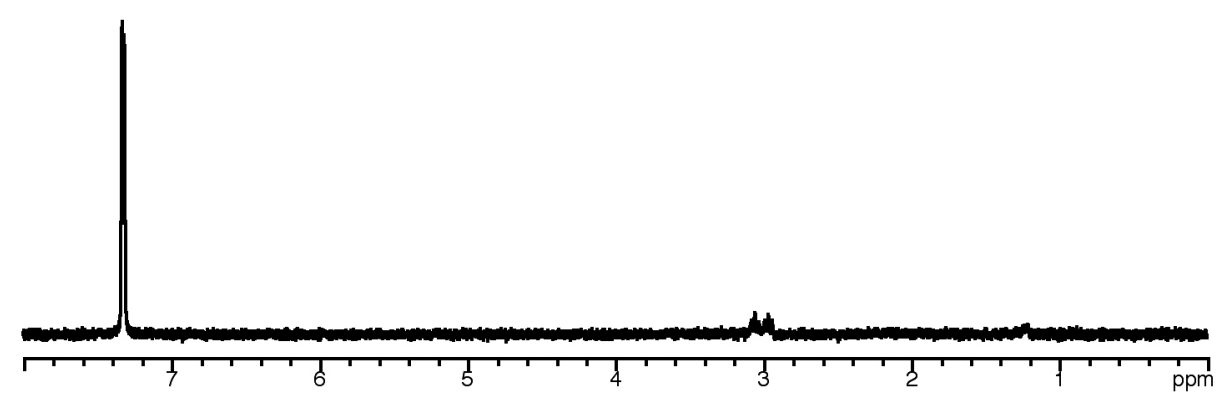

Figure 5. Tritium-NMR of the tritiated product from the reaction of amide $\mathbf{5}$ with complex 4b (Scheme 5).

As is widely recognised, the production of tritiated impurities and by-products during the HIE process can lead to significant waste disposal problems. In this respect, Figure 6 shows a radiochromatogram of the crude reaction mixture from a tritiation of an AstraZeneca research compound when employing $100 \mathrm{~mol} \%$ of Crabtree's catalyst (as was standard in our laboratories in order to achieve acceptable levels of labelling). As can be seen from the chromatogram, a plethora of radioactive materials have been produced, with only a very small peak corresponding to the tritiated compound of interest. On the other hand, analysis of the crude reaction mixture carried out using a carbene catalyst $\mathbf{4 c}$ and the same AstraZeneca substrate shows a remarkable improvement (Figure 7). Using only $5 \mathrm{~mol} \%$ of the catalyst, a significantly enhanced quantity of the desired tritiated compound is obtained, whilst the reaction is exceedingly clean, with tritiated water as the only significant labelled by-product. This large reduction in radioactive by-product formation is a clear advantage of these complexes when compared to Crabtree's catalyst and could aid the pharmaceutical industry in managing waste issues, with benefits in terms of both disposal costs and environmental pollution. 


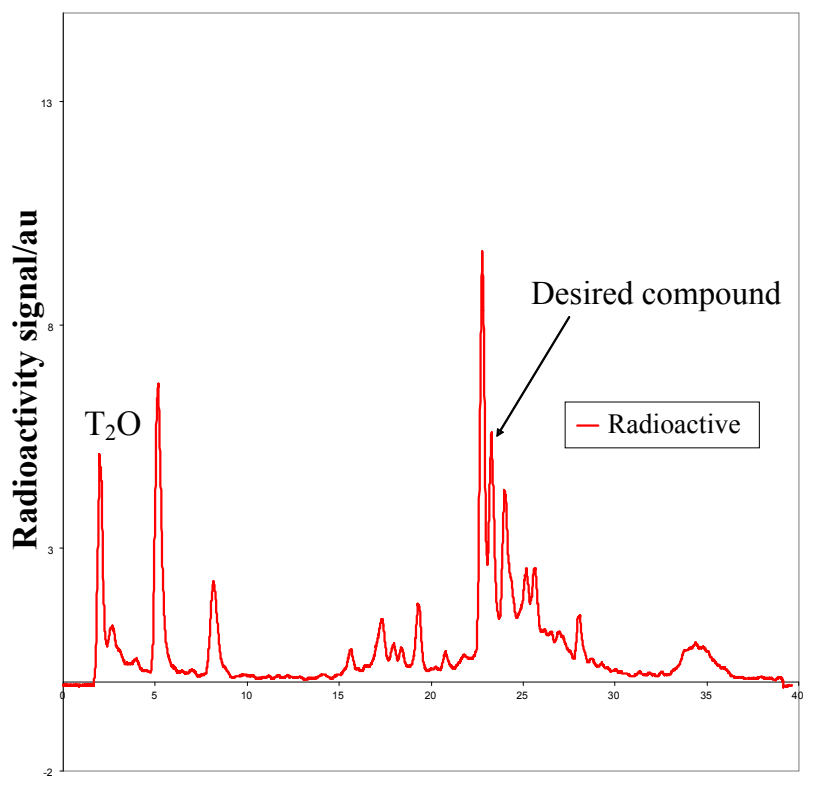

Retention time/minutes

Figure 6. Radiochromatogram from the crude reaction mixture following a tritiation with Crabtree's catalyst (100 mol\%).

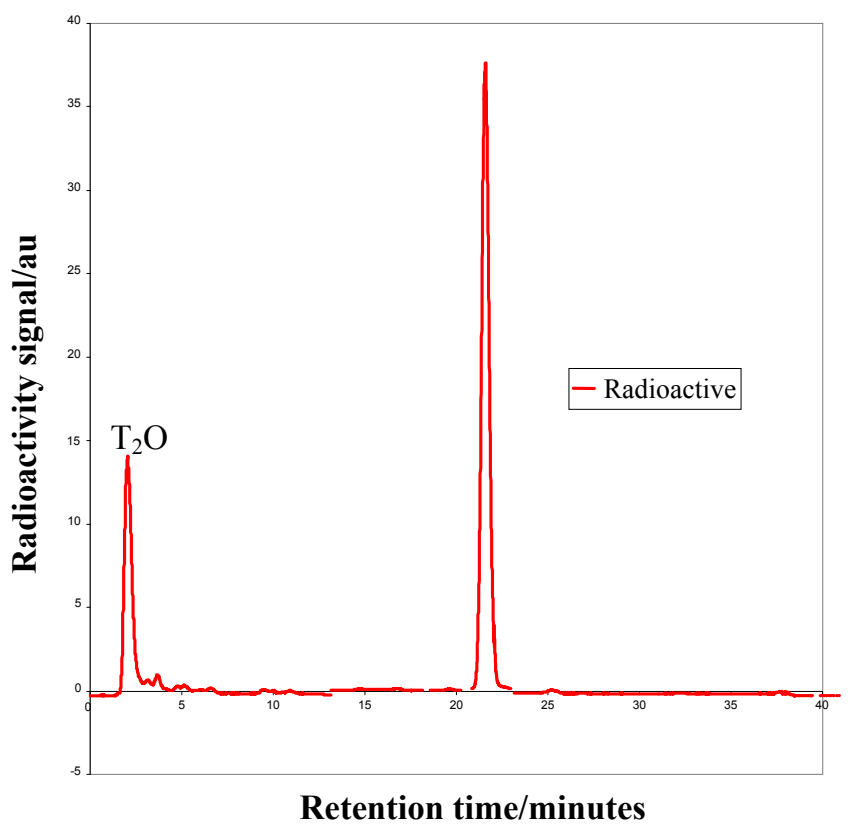

Figure 7. Radiochromatogram from the crude reaction mixture following a tritiation with complex $4 \mathrm{c}(5 \mathrm{~mol} \%)$.

Comparison of the Iridium Carbene Catalysts with Crabtree's Catalyst

From the discussion in the preceding section, the advantages of the novel Kerr carbene catalysts over Crabtree's catalyst 1 should be apparent in terms of labelling efficiencies at low catalyst loadings over short reaction times, exchange selectivities, and reaction 
cleanliness. In more specific terms, the high (and selective) HIE levels achieved with nilutamide with only $2.5 \mathrm{~mol} \%$ of $4 \mathbf{c}$ over $1 \mathrm{~h}$ at room temperature (Scheme 3 ) can be directly compared to that observed with 1 under the same reaction conditions, where less than $6 \%$ labelling was obtained at each of the three sites in the molecule. Similarly, under equivalent conditions to those detailed in Scheme 4, when Crabtree's catalyst 1 was employed with niclosamide less than $15 \%$ incorporation was obtained at positions a and d only.

\section{Conclusions}

As detailed here, this collaborative programme of work has revealed the considerable efficiency and general applicability of the specific group of novel iridium(I) complexes 4a-c within iridium-catalysed $\mathrm{C}-\mathrm{H}$ activation chemistry and hydrogen isotope exchange. The combined phosphine and bulky NHC ligands employed have led to catalysts which are highly active and which deliver high incorporations of deuterium or tritium into drug-like molecules, whilst tolerating a wide range of functional moieties. Furthermore, catalyst loadings as low as only $0.5 \mathrm{~mol} \%$ and short reaction times have been shown to provide extremely effective levels of labelling with a range of substrates.

Iridium complexes 4a-c have also been applied within isotopic labelling endeavours as part of our drug development processes. In this regard, the low catalyst loadings and short reaction times made possible by these new species have delivered tritiated products with very good levels of labelling and without any appreciable tritiated waste. Therefore, this emerging class of iridium catalysts have the clear potential to replace Crabtree's catalyst $\mathbf{1}$ as the industry standard in this area.

\section{Experimental}

All syntheses of the catalysts were carried out under inert atmosphere in dry glassware. The screening reactions were carried out under a deuterium or carrier-free tritium atmosphere on a stainless steel manifold purchased from RC TRITEC AG, Teufen (Switzerland). Deuterium gas was purchased from AGA (Sweden) and tritium gas was purchased from RC TRITEC AG. All reagents were purchased from commercial suppliers (Sigma-Aldrich, Alfa Aesar or Strem) and were without further purification. The solvents use in catalyst preparation, tetrahydrofuran, diethyl ether and benzene, were dried by heating to reflux over sodium wire, using benzophenone ketyl as an indicator, and then distilled under nitrogen. Dichloromethane was dried by heating to reflux over calcium hydride then distilled under nitrogen. LC-MS was performed using an Agilent 1100 series chromatograph on a Synergi Max RP column $(3 \times 50 \mathrm{~mm}, \mathrm{C} 12,4 \mu)$ with gradient elution (using a linear gradient of $\mathrm{MeCN}$ in $\mathrm{H}_{2} \mathrm{O}, \mathrm{pH}=4$ ) with analysis via a Waters Micromass ZQ mass spectrometer with either APPI+ or ES+ ionisation.

${ }^{1} \mathrm{H}$ and ${ }^{13} \mathrm{C}$ NMR spectra were recorded on a Bruker DPX 400 spectrometer at $400 \mathrm{MHz}$ and $100 \mathrm{MHz}$, respectively. Tritium-NMR spectra were recorded on a Varian Inova 500 spectrometer at $534 \mathrm{MHz}$ using a Nalorac $5 \mathrm{~mm}$ tritium probe with a double tuned coil for ${ }^{1} \mathrm{H} /{ }^{3} \mathrm{H}$. The incorporation of deuterium or tritium per molecule was determined by ${ }^{1} \mathrm{H}$ NMR or LC-MS and calculated with NAIC $1.2 .{ }^{33}$ 


\section{General preparation of the carbene catalysts}

An approximately $1 \mathrm{M}$ solution of sodium ethoxide was prepared by dissolving sodium metal $(0.25 \mathrm{~g})$ in ethanol $(10 \mathrm{~mL})$ in a previously flame-dried flask under argon.

To a solution of $\eta^{4}$-cycloocta-1,5-dieneiridium(I) chloride dimer, in dry benzene (10 $\mathrm{mL}$ ) in a previously flame-dried Schlenk tube under argon, was added the $1 \mathrm{M}$ sodium ethoxide solution and a colour change from orange to yellow was observed. After stirring at room temperature for 10 minutes, 1,3-dimesitylimidazolium chloride was added as one portion and the solution was stirred under argon for $5 \mathrm{~h}$. After this time, the solvent was removed under high vacuum and the orange residue was triturated with dry diethyl ether $(15 \mathrm{~mL})$ and filtered through Celite under argon. The solvent was concentrated in vacuo to yield a yellow solid which was dissolved in THF (15 mL) to give a yellow solution. Addition of solid silver hexafluorophosphate caused a colour change to orange and this solution was stirred for 20 minutes, prior to filtration through Celite under argon. To this orange solution was added the phosphine and the now deep red solution was stirred for 1-2 h. After this time, the solvent was concentrated in vacuo and the product isolated by recrystallisation from DCM/diethyl ether.

\section{General HIE reaction conditions}

To a small round-bottomed flask was added the substrate and the iridium complex as a solution in dry dichloromethane $(0.5 \mathrm{~mL})$. The flask was fitted to a TRITEC ${ }^{\circledR}$ manifold, immersed in a bath of liquid nitrogen, degassed using the freeze/thaw method, and was then filled with deuterium or tritium gas via the manifold. The flask was removed from the bath and allowed to warm to room temperature and the reaction was allowed to stir vigorously at room temperature for the allotted reaction time. After this time, the dichloromethane and any volatile deuterium or tritium was removed under a stream of nitrogen, and the flask refilled with methanol and evaporated (twice). The catalyst complex was precipitated using diethyl ether and removed by filtration through a plug of silica. Concentration of the filtrate under reduced pressure yielded the product which was analysed by ${ }^{1} \mathrm{H}$ and tritium-NMR to determine the position (and extent) of labelling, and by LC/MS to determine the level of incorporation.

\section{Acknowledgements}

The authors also wish to thank the past and present members of the Isotope Chemistry team at AstraZeneca R\&D Mölndal, and Dr. Stephanie Irvine for important discussions and contributions. WJK also gratefully acknowledges the EPSRC Mass Spectrometry Service, University of Wales, Swansea, for analyses. During the preparation of this review, Billy Deutz assisted with creative and valuable contributions. 


\section{Graphical Abstract}

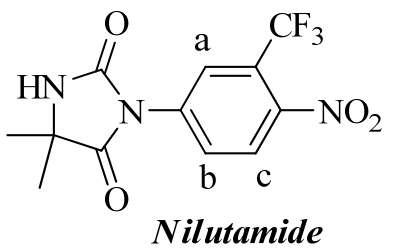

Nilutamide

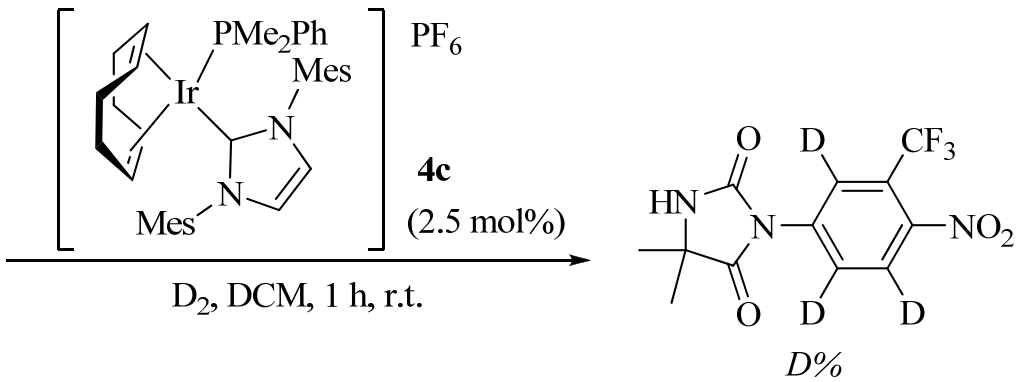

a: $6 \% ;$ b: $12 \%$; c: $98 \%$

\section{References}

${ }^{1}$ R. Crabtree, H. Felkin, G. E. Morris, J. Organomet. Chem. 1977, 141, 205-215.

2 (a) R. Salter, M. Chappelle, A. Morgan, T. Moenius, P. Ackermann, M. Studer, F. Spindler, Synthesis and Applications of Isotopically Labelled Compounds, Vol. 7, John Wiley and Sons Ltd, Chichester, 2001, 7, 63-67; (b) D. Hesk, P. R. Das, B. Evans, J. Label. Compd. Radiopharm. 1995, 36, 497-502.

${ }^{3}$ G. J. Ellames, J. S. Gibson, J. M. Herbert, A. H. McNeill, Tetrahedron 2001, 57, 9487-9497.

${ }^{4}$ R. Salter, I. Bosser, J. Label. Compd. Radiopharm. 2003, 46, 489-498.

${ }^{5}$ A. Y. L. Shu, D. Saunders, S. H. Levinson, S. W. Landvatter, A. Mahoney, S. G. Senderoff, J. F. Mack, J. R. Heys, J. Label. Compd. Radiopharm. 1999, 42, 797-807.

${ }^{6} 50^{\text {th }}$ Anniversary Special Issue, in Memoriam John Jones, J. Label. Compd. Radiopharm. 2007, 50, 735-943.

${ }^{7}$ J. Atzrodt, V. Derdau, T. Fey, J. Zimmermann, Angew. Chem. Int. Ed. 2007, 46, 7744-7765.

${ }^{8}$ R. Voges, J. R. Heys, T. Moenius, Preparation of Compounds Labeled with Tritium and Carbon-14, John Wiley and Sons Ltd, Chichester, 2009, Chapter 3.

${ }^{9}$ J. R. Heys, M. E. Powell, D. E. Pivonta, J. Label. Compd. Radiopharm. 2004, 47, 983-995.

${ }^{10}$ J. R. Heys, C. S. Elmore, J. Label. Compd. Radiopharm. 2009, 52, 189-200.

${ }^{11}$ S. C. Schou, J. Label. Compd. Radiopharm. 2009, 52, 376-381.

${ }^{12}$ W. J. S. Lockley, J. Label. Compd. Radiopharm. 2007, 50, 779-788 and references cited therein.

${ }^{13}$ N. Bushby, D. A. Killick, J. Label. Compd. Radiopharm. 2007, 50, 519-520.

${ }^{14}$ R. Salter, I. Bosser, J. Label. Compd. Radiopharm. 2003, 46, 489-498.

${ }^{15}$ M. J. Hickey, L. P. Kingston, W. J. S. Lockley, A. N. Mather, D. J. Wilkinson, J. Label. Compd. Radiopharm. 2006, 49, 388-389.

${ }^{16}$ W. Chen, K. T. Garnes, S. H. Levinson, D. Saunders, S. G. Senderoff, A.Y. L. Shu, A. J. Villani, J. R. Heys, J. Label. Compd. Radiopharm. 1997, 39, 291-298.

${ }^{17}$ J. T. Singleton, Tetrahedron 2003, 59, 1837-1857 and references cited therein.

${ }^{18}$ M. E. van der Boom, D. Milstein, Chem. Rev. 2003, 103, 1759-1792 and references cited therein.

${ }^{19}$ C. J. Moulton, B. L. Shaw, J. Chem. Soc., Dalton Trans. 1976, 1020-1024.

${ }^{20}$ M. Gupta, C. Hagen, R. J. Flesher, W. C. Kaska, C. M. Jensen, Chem. Commun. 1996, 2083-2084.

${ }^{21}$ K. Wang, M. E. Goldman, T. J. Emge, A. S. Goldman, J. Organomet. Chem. 1996, 518, 55-68.

${ }^{22}$ W. Leitner, C. Six, Chem. Ber. 1997, 130, 555-558.

${ }^{23}$ I. Göttker-Schnetmann, P. White, M. Brookhart, J. Am. Chem. Soc. 2004, 126, 1804-1811.

${ }^{24}$ J. Zhao, A. S. Goldman, J. F. Hartwig, Science 2005, 307, 1080-1082.

${ }^{25}$ A. Träff, G. N. Nilsson, K. J. Szabó, L. Eriksson, J. Organomet. Chem. 2007, 692, 5529-5531.

${ }^{26}$ M. H. G. Prechtl, M. Hölscher, Y. Ben-David, N. Theyssen, R. Loschen, D. Milstein, W. Leitner, Angew. Chem. Int. Ed., 2007, 46, 2269-2272.

${ }^{27}$ (a) R. Heys, J. Chem. Soc., Chem. Commun. 1992, 680681; (b) J. R. Heys, A. Y. L. Shu, S. G. Senderoff, N. M. Phillips, J. Label. Compd. Radiopharm. 1993, 33, 431-438; (c) A. Y. L. Shu, W. Chen, J. R. Heys, J. Organomet. Chem. 1996, 524, 87-93; (d) J. G. Ellames, J. S. Gibson, J. M. Herbert, W. J. Kerr, A. H. McNeill, Tetrahedron Lett. 2001, 42, 6413-6416; (e) P. W. C. Cross, J. G. Ellames, J. S. Gibson, J. M. Herbert, W. J. Kerr, A. H. McNeill, T. W. Mathers, Tetrahedron 2003, 59, 3349-3358; (f) J. G. Ellames, J. S. Gibson, J. M. Herbert, W. J. Kerr, A. H. McNeill, J. Label. Compd. Radiopharm. 2004, 47, 1-10; (g) M. B. Skaddan, C. M. Yung, R. G. Bergman, Org. Lett. 2004, 6, 11-13; (h) C. M. Yung, M. B. Skaddan, R. G. Bergman, J. Am. Chem. Soc. 2004, 126, 13033-13043; (i) R. N. Garman, M. J. Hickey, L. P. Kingston, B. McAuley, J. R. Jones, W. J. S. Lockley, A. N. Mather, D. J. Wilkinson, J. Label. Compd. Radiopharm. 2005, 48, 75-84; (j) J. Krüger, B. Manmontri, G. Fels, 
Eur. J. Org. Chem. 2005, 1402-1408; (k) M. B. Skaddan, R. G. Bergman, J. Label. Compd. Radiopharm. 2006, 49, 623-634.

${ }^{28}$ H. M. Lee, T. Jiang, E. D. Stevens, S. P. Nolan, Organometallics 2001, 20, 1255-1258.

${ }^{29}$ (a) L. D. Vásquez-Serrano, B. T. Owens, J. M. Buriak, Chem. Commun. 2002, 2518-2519; (b) L. D. VasquezSerrano, B. T. Owens, J. M. Buriak, Inorg. Chim. Acta 2006, 359, 2786-2797.

${ }^{30}$ J. A. Brown, S. Irvine, A. R. Kennedy, W. J. Kerr, S. Andersson, G. N. Nilsson, Chem. Commun. 2008, $1115-$ 1117.

${ }^{31}$ M. E. Powell, C. S. Elmore, P. N. Dorff, J. R. Heys, J. Label. Compd. Radiopharm. 2007, 50, 523-525.

${ }^{32}$ S. Irvine, PhD Thesis, University of Strathclyde, Glasgow, UK, 2009.

${ }^{33}$ K. N. D. Barakzai, B. J. Howlin, W. J. S. Lockley, K. Sfyrakis, J. Label. Compd. Radiopharm. 2009, 52, 559562. 